Cad. Líng. Lit. Hebr., n. 15, p. 270-279, 2017

\title{
A REMEMORAÇÃO COMO RECURSO FORMAL: NOTAS ACERCA DE UMA ENTREVISTA A PRIMO LEVI
}

\section{THE REMEMBRANCE AS A FORMAL ELEMENT: NOTES UPON AN INTERVIEW WITH PRIMO LEVI}

\author{
Raphael Fortin*
}

\section{RESUMO}

Partindo do conceito benjaminiano de rememoração, este texto busca investigar de que forma é possível considera-lo operacional, tendo como corpus de análise uma entrevista concedida por Primo Levi a um programa da televisão italiana e partes de sua produção literária. Dessa forma, pretende-se refletir sobre o caráter dessas produções, sobretudo enfocando alguns de seus aspectos formais que colocam questões acerca da representação da Shoá e da necessidade da escuta.

Palavras-chave: rememoração; Primo Levi; Shoá.

\begin{abstract}
Starting from Benjamin's concept of remembrance, this text seeks to investigate how it is possible to consider it operational, having as corpus of analysis an interview granted by Primo Levi to an Italian television program and parts of his literary production. In this way, we intend to reflect on the character of these productions, mainly focusing on some of their formal aspects that raise questions about the representation of the Shoah and the need for listening.
\end{abstract}

Keywords: remembrance; Primo Levi; Shoah.

\footnotetext{
* Graduando em Letras na Universidade de São Paulo (FFLCH - USP).
} 
FORTIN, Raphael. A rememoração como Recurso Formal: Notas acerca de uma Entrevista a Primo Levi

Em 1997, em homenagem ao décimo aniversário de morte do escritor Primo Levi, o RAI 2 (popular canal da televisão italiana) exibiu o programa Ritorno ad Auschwitz. Trata-se de um capítulo de um projeto maior (Sorgente di Vita) que visava apresentar e esmiuçar questões relacionadas à cultura da comunidade de judeus italianos. Evidentemente, por ser uma homenagem póstuma, o pequeno documentário foi filmado em 1982, 15 anos antes de sua exibição, e concentra-se na experiência de Primo Levi à Polônia, 40 anos depois de sua libertação do campo de concentração.

O programa tem duração de trinta minutos e consiste em uma entrevista realizada, em grande parte, durante o percurso de trem que leva até Auschwitz. A película foi dirigida por Daniel Toaff, que é também o entrevistador, conta com a montagem de Milko Duiella e fotografia de Ildo Chiappin e Jerzy Jedrzejczyk. As perguntas são marcadas por um certo didatismo e simplicidade, onde o que verdadeiramente importa são as impressões de Primo Levi. Isso parece ser uma estratégia formal bastante interessante que coloca em foco a rememoração.

O objetivo desse ensaio, tendo como corpus de análise principal a entrevista de Primo Levi e alguns trechos de sua produção literária, é aproximar essa breve narrativa do movimento de rememoração (Eingedenken), conceito presente na obra de Walter Benjamin, sobre o qual se debruçaram diversos estudiosos. Dessa forma, convém, inicialmente, elucidar esse conceito, enfatizando os aspectos que parecem mais importantes para a aproximação que se busca fazer.

Em suas Teses sobre o conceito de História ${ }^{1}$, a rememoração aparece, sobretudo, como um contraponto, uma crítica ao historicismo que, por sua vez, constituía uma abordagem de cunho positivista, buscando detectar a "verdade", o "fato puro" no passado. As

${ }^{1}$ LÖWY, 2005. 
Cad. Líng. Lit. Hebr., n. 15, p. 270-279, 2017

teses chamam a atenção para o fato de essa abordagem "não levar em conta a posição do historiador enquanto sujeito de um determinado presente e de não considerar este presente como parte integrante da história" ${ }^{2}$. Nesse sentido, para que aconteça o movimento de rememoração, não basta apenas a evocação do passado, faz-se necessário relacioná-lo ao presente, agir sobre ele, porque o presente constitui um momento decisivo, o momento da ação.

Maior que a necessidade de se lembrar do passado, é colocá-lo em diálogo com o tempo presente, exercício realizado pela rememoração. A tradição judaica sempre exigiu a rememoração do passado, o verbo zakhor (lembrar) aparece 169 vezes em sua bíblia, como observa Yossef Hayim Yerushalmi: “o que os judeus buscam no passado não é sua historicidade, mas sua eterna contemporaneidade"3. Não é à toa que após o genocídio da Segunda Guerra Mundial surgiu o que hoje convencionou-se chamar de "literatura de testemunho”. Para os sobreviventes judeus da Shoá, lembrar-se não significa apenas manter viva a voz daqueles que não tem direito à palavra, mas a lembrança é, antes de mais nada, necessária para a transformação do presente, reincidindo sobre a máxima adorniana de lembrar para que não se repita.

Em sua obra É isto um homem?, no capítulo "As nossas noites”, Primo Levi nos narra um sonho constante que teve enquanto preso em Auschwitz: são e salvo já em casa, ele está entre a família e seus amigos narrando suas experiências:

Aqui está minha irmã, e algum amigo (qual?), e muitas outras pessoas. Todos me escutam, enquanto conto do apito em três notas, da cama dura, do vizinho que gostaria de empurrar para o lado, mas tenho medo de acordá-lo porque é mais forte que eu. Conto também a história da nossa fome, e do controle dos piolhos, e do Kapo que me deu um soco no nariz e logo mandou que me lavasse porque sangrava. É uma felicidade interna, física, inefável,

\footnotetext{
${ }^{2}$ OTTE, 1996, p. 213.

${ }^{3}$ apud LÖWY, 2005, p.142
} 
FORTIN, Raphael. A rememoração como Recurso Formal: Notas acerca de uma Entrevista a

Primo Levi

estar em minha casa, entre pessoas amigas, e ter tanta coisa para contar, mas bem me apercebo de que eles não me escutam. Parecem indiferentes; falam entre si de outras coisas, como se eu não estivesse. Minha irmã olha para mim, levanta, vai embora em silêncio. (grifos meus) ${ }^{4}$

Algo inesperado, porém, machuca-o mais do que a fome, a violência do Kapo, a cama dura, as pragas: ao tentar narrar suas experiências percebe que as pessoas ao seu redor não o escutam e, pior, demonstram indiferença à narração:

Nasce então, dentro de mim, uma pena desolada, como certas mágoas da infância que ficam vagamente em nossa memória; uma dor não temperada pelo sentido da realidade ou a intromissão de circunstâncias estranhas, uma dor dessas que fazem chorar as crianças. Melhor, então, que eu torne mais uma vez à tona, que abra bem os olhos; preciso estar certo de que acordei, acordei mesmo. ${ }^{5}$

Dar voz à memória nunca foi tarefa tão simples; a posição de um narrador diante do indizível é de extrema complexidade. Benjamin em seu ensaio $O$ narrador insiste na perda da fala após a Primeira Grande Guerra, em que os sobreviventes que voltaram das trincheiras, voltaram mudos, pois aquilo que vivenciaram não podia ser mais assimilado por palavras.

Jeanne Marie Gagnebin, em seu livro intitulado Lembrar escrever esquecer (2009), diz que "a perda da experiência acarreta um outro desaparecimento, o das formas tradicionais de narrativa, de narração, que têm sua fonte nessa comunidade e nessa transmissibilidade”. Por mais que os livros de testemunho escritos pelos judeus da Shoá tentem dar voz às suas experiências, continuar tratando o genocídio como hiato como faz a história positivista e ignorando e denegando sua existência como, até hoje, faz a política internacional, será como se "houvesse herdeiros de mortos que, simbolicamente falando, nunca existiram, que não

\footnotetext{
${ }^{4}$ LEVI, 1988, p. 85.

${ }^{5}$ Idem.
} 
Cad. Líng. Lit. Hebr., n. 15, p. 270-279, 2017

pertenceram aos vivos e não podem, portanto, pertencer hoje aos mortos, tornando seu luto tão difícil’”.

O sonho está na minha frente, ainda quentinho; eu, embora desperto, continuo, dentro, com essa angústia do sonho; lembro, então, que não é um sonho qualquer; que, desde que vivo aqui, já o sonhei muitas vezes, com pequenas variantes de ambiente e detalhes. Agora estou bem lúcido, recordo também eu já contei o meu sonho a Alberto e que ele me confessou que esse é também o sonho dele e o sonho de muitos mais; talvez de todos. Por quê? Por que o sofrimento de cada dia se traduz, constantemente, em nossos sonhos, na cena sempre repetida da narração que os outros não escutam? ${ }^{7}$

Narrar, lembrar, relembrar é de extrema importância, mas ouvir é ainda mais necessário, pois ignorá-los ou mesmo silenciar-se, como faz a irmã de Levi no sonho, é calar mais uma vez os sobreviventes e os mortos da Shoá como os nazistas tanto se empenharam em fazer com a animalização e as câmaras de gás dos segundos, é conformar-se com a história progressista dos opressores e com os assassinatos que cometeram, é encobrir as ruínas e fingir que nunca existiram.

A função dos ouvintes, daqueles que no sonho de Primo Levi não cumprem com o esperado pois não querem saber, ignoram, não escutam com medo de que essa história "ameace sua linguagem ainda tranquila", é a de retomar e transmitir a história em sua contemporaneidade, para que sirva de lição para o presente e para o futuro, como conclui Jeanne Marie Gagnebin em seu texto:

Testemunha também seria aquele que não vai embora, que consegue ouvir a narração insuportável do outro e que aceita que suas palavras levem adiante, como num revezamento, a história do outro: não por culpabilidade ou por compaixão, mas porque somente a transmissão simbólica, assumida apesar e por causa do sofrimento indizível, somente essa retomada reflexiva do

\footnotetext{
${ }^{6}$ GAGNEBIN, 2009, p. 56.

${ }^{7}$ LEVI, 1988, p. 85-86.

${ }^{8}$ GAGNEBIN, 2009, p. 57.
} 
FORTIN, Raphael. A rememoração como Recurso Formal: Notas acerca de uma Entrevista a Primo Levi

passado pode nos ajudar a não repetí-lo infinitamente, mas a ousar esboçar uma outra história, a inventar o presente. ${ }^{9}$

Dito isso, e situando Primo Levi dentro dessa linhagem de reflexões, compreendendo que questões como essa perpassam sua obra, partimos, então, para o comentário mais atento de algumas passagens do documentário.

Partindo das ideias de George Steiner, pode-se pensar que a própria linguagem se encontra em crise como elemento essencial da história humana. Steiner questiona a visão da cultura enquanto força humanizadora e chama atenção para a importância do silêncio, como algo que interpela a própria capacidade de dizer, tendo como interesse pensar o silêncio como forma de resistir à banalização da linguagem e seu esvaziamento, situação que se intensifica com a barbárie imposta pelo nazismo ${ }^{10}$. Nesse sentido, a brevidade do relato e uma certa objetividade em relação às perguntas realizadas podem apontar para a importância desse silêncio como forma de construção formal. O silêncio implica em uma materialidade criativa onde residem inúmeros significados, portanto, enfatizando também a dimensão do não-dito, do implícito pela impossibilidade de dizer.

Há, entretanto, contradições marcadas por um certo sensacionalismo observado em alguns dos recursos formais. Aqui, chama-se a atenção para a música dramática que opera enquanto trilha sonora nos momentos em que o documentário exibe imagens históricas oficiais do período. Esses momentos representam uma quebra dentro da própria proposta do documentário, a fala de Primo Levi não aparece e, nesses momentos, o que temos são essas imagens sobrepostas a uma música que tem a única função de ativar um suposto lado emotivo

\footnotetext{
${ }^{9}$ GAGNEBIN, 2009, p. 57.

${ }^{10}$ STEINER, 1988.
} 
Cad. Líng. Lit. Hebr., n. 15, p. 270-279, 2017

do espectador. Ao contrário do não-dito, o que percebemos nesse momento é um excesso, algo que não parece servir a nenhum propósito formal, exceto o do ornamento.

É interessante observar como as perguntas são conduzidas de modo a enfatizar uma reconstrução das memórias de Primo Levi. O entrevistador sempre o questiona a partir de sua própria experiência. "Como é retornar aqui de um hotel de luxo?", "O que os trens de carga te fazem pensar?", “Como foi a viagem de 5 dias para os campos? Recorda-se?”, são alguns exemplos das perguntas direcionadas a Primo Levi. Nessa última, por exemplo, o escritor dá uma série de detalhes a respeito do acontecimento, fala sobre o número de pessoas no vagão, sobre as condições de habitação naquele pequeno espaço etc. Opera, de fato, um trabalho de rememoração, reconstruindo suas lembranças que dizem respeito, não somente a uma experiência individual, mas também conduzem o ouvinte atento a reconstrução de uma memória que é coletiva.

Ainda, ao final do documentário, são propostas duas questões de caráter mais geral, sendo a primeira delas "O que representa o Holocausto para o povo judeu?”. De início, Primo Levi diz que o genocídio do povo judeu não é algo novo e que esse episódio da história revelou um novo aspecto do antissemitismo. Além disso, critica o uso do termo "Holocausto", crítica corroborada por diversos pensadores judeus; Primo considera que o uso desse termo constitui uma mudança axial, isto é, uma acepção formal que não dá conta de apreender o fenômeno em suas particularidades.

Sobretudo, o que mais nos chama atenção na resposta de Primo Levi a essa pergunta é quando caracteriza a Shoá como algo inédito porque foi arquitetado e desejado. A respeito disso, em Barbárie e modernidade no século $X X$, Michael Löwy nos introduz ao termo "barbárie civilizada" para caracterizar um tipo de violência bastante específico do século XX. Citando Norbert Elias, aponta para uma violência que: 
(...) não é mais exercida de maneira espontânea, irracional e emocional pelos indivíduos, mas é monopolizada e centralizada pelo Estado, mais precisamente, pelas forças armadas e pela polícia. Graças ao processo civilizador, as emoções são controladas, o caminho da sociedade é pacificado e a coerção física fica concentrada nas mãos do poder político. ${ }^{11}$

E, ao longo do texto, tratando de Auschwitz, continua:

Auschwitz não representa uma "regressão" em direção ao passado, em direção a uma idade bárbara primordial, mas é realmente um dos rostos possíveis da civilização industrial ocidental. Ele constitui ao mesmo tempo uma ruptura com a herança humanista e universalista dos Iluministas e um exemplo terrível das potencialidades negativas e destrutivas de nossa civilização. ${ }^{12}$

Ambos, Primo Levi e Michael Löwy, nos chamam a atenção para características da barbárie que são propriamente modernas, não somente pela fabricação da morte de maneira organizada e com técnicas avançadas, mas também pelo burocratismo, pela ideologia pseudocientífica que dá um caráter racional, transformando a logos em uma força destrutiva.

A segunda pergunta mais geral é "Pode materializar-se o aniquilamento do homem pelo homem?”. Aqui, Primo Levi aponta para uma das características fundamentais dos campos de concentração que consistia no aniquilamento da humanidade interior e exterior. Além disso, comenta como a animalização era enfatizada até mesmo pelo uso da linguagem. Para explicitar essa relação linguística, comenta sobre a utilização dos verbos fressen e essen. Ambas as formas verbais, em alemão, significam comer. Entretanto, enquanto fressen é utilizado em um sentido mais animalesco, equivalente ao devorar, em português, essen é utilizado no sentido mais tradicional e corrente do verbo. Dito isso, Levi comenta como os

\footnotetext{
${ }^{11}$ apud LÖWY, s.d., p. 1.

${ }^{12}$ LÖWY, s.d., p. 6.
} 
Cad. Líng. Lit. Hebr., n. 15, p. 270-279, 2017

próprios judeus começaram a se referir a seus atos de alimentação com a forma fressen, internalizando o processo de animalização provocado pelos nazistas.

Por fim, gostaria de chamar a atenção para a definição de rememoração, proposta por Jeanne Marie Gagnebin, dada a sua pertinência diante do tema discutido:

Proporia, então, uma distinção entre a atividade de comemoração, que desliza perigosamente para o religioso ou, então, para as celebrações de Estado, com pardas e bandeiras, e um outro conceito, o de rememoração, assim traduzindo aquilo que Benjamin chama de Eingedenken, em oposição à Erinnerung de Hegel e às várias formas de apologia. Tal rememoração implica uma certa ascese da atividade historiadora que, em vez de repetir aquilo de que se lembra, abre-se aos brancos, aos buracos, ao esquecido e ao recalcado, para dizer, com hesitações, solavancos, incompletude, aquilo que ainda não teve direito nem à lembrança nem às palavras. A rememoração também significa uma atenção precisa ao presente, em particular a estas estranhas ressurgências do passado no presente, pois não se trata somente de não se esquecer do passado, mas também de agir sobre o presente. A fidelidade ao passado, não sendo um fim em si, visa à transformação do presente. $^{13}$

Nesse sentido, a forma como constrói seu documentário, exigindo uma postura ativa do espectador que vai preenchendo essas lacunas do silêncio, posicionando-se frente a um acontecimento histórico tão terrível, é a maneira que encontra para produzir uma transformação ativa no presente. Não adornando um evento histórico, mas sim, rememorandoo para que não se esqueça e para que sirva de exemplo à contemporaneidade. Primo Levi diz, ao final do documentário, não acreditar que a Shoá possa se repetir na Europa, baseando-se numa espécie do que chama de imunização do trauma. Entretanto, suas memórias nos deixam um aviso de incêndio. Esse aviso fica marcado, sobretudo, por um de seus últimos comentários. Ele nos diz que a ideia não morreu, o antissemitismo permanece vivo, apenas mudou de forma e finaliza dizendo que, embora não acredite que o trauma possa se repetir na

\footnotetext{
${ }^{13}$ GAGNEBIN, 2009, p. 55.
} 
FORTIN, Raphael. A rememoração como Recurso Formal: Notas acerca de uma Entrevista a Primo Levi

Europa: "Mas o mundo não se acaba em Europa". Pensar a escuta como ética e o ouvinte como testemunha, eis a tarefa.

\section{Referências Bibliográficas}

GAGNEBIN, Jeanne Marie. Lembrar escrever esquecer. São Paulo: Editora 34, 2009.

LEVI, Primo. É isto um homem?. Rio de Janeiro: Rocco, 1988.

LÖWY, Michael. Walter Benjamin: aviso de incêndio: uma leitura das teses "Sobre o conceito de história”. São Paulo: Boitempo, 2005.

. Barbárie e modernidade no século XX. Tradução de Alessandra Ceregatti,

s.d. Disponível em: [http://www.egov.ufsc.br/portal/pt-br/conteudo/barb\%C3\%A1rie-emodernidade-no-s\%C3\%A9culo-xx]. Acessado em 02 de julho de 2017.

OTTE, Georg. "Rememoração e citação em Walter Benjamin". In: Aletria: Revista de Estudos de Literatura. Belo Horizonte, v. 4, 1996, p. 213.

STEINER, G. Linguagem e silêncio. São Paulo: Companhia das Letras, 1988. 